\title{
Crescimento econômico secular no Brasil, modelo de Thirlwall e termos de troca ${ }^{1}$
}

\author{
Fabrício de Assis C. Vieira ${ }^{2}$ \\ Márcio Holland ${ }^{3}$
}

\section{Resumo}

Explicar o crescimento econômico brasileiro no século XX é realmente desafiador. Como mostrado no trabalho, o Brasil já experimentou melhores taxas de crescimento e atualmente o país se encontra distante da belle époque. Este trabalho analisa o modelo de Thirlwall de restrição no balanço de pagamentos para o crescimento econômico brasileiro no período 1900-2005, destacando a importância dos termos de troca. Os resultados mostraram que os termos de troca são significativos na função de demanda por importações, alterando a elasticidade-renda, especialmente no subperíodo 1900-1970, e, segundo, que quando o modelo mais simples de Thirlwall é controlado pelos termos de troca, parece que tal variável afeta a performance econômica do país através das taxas de crescimento das importações.

Palavras-chave: Brasil - Condições econômicas; Desenvolvimento econômico; Termos de troca; Balanço de pagamentos - Restrição; Lei de Thirlwall.

\begin{abstract}
Long-run economic growth in Brazil, Thirlwall's model and terms of trade

Explaining the Brazilian economic growth performance during the $20^{\text {th }}$ is a challenging task to academics. As shown, Brazil had already experienced faster growth and recently it is far from such belle époque. Most explanations are based on conventional frameworks. This paper assesses the Balance-of-Payments constraint model to Brazilian economic growth in the period 1900-2005, highlighting the importance of the terms of trade. The results show, first, that the terms of trade are significant in the estimation of import demand function and change the income elasticity, especially in the first period of the sample (1900-1970), and, second, when the simplest Thirlwall's model is controlled by terms of trade, it seems that such variable is important through import growth, which cause changes in economic performance.
\end{abstract}

Key words: Brazilian economic growth; Terms of trade; Balance-of-Payments Constraint; Thirlwall's law.

JEL C22; E01; F10; O10.

(1) Trabalho recebido em março de 2007 e aprovado em outubro de 2007. Os autores agradecem aos pareceristas anônimos pelos seus valiosos comentários e sugestões de revisão de versão submetida originalmente.

(2) Mestre em Economia e Doutorando em Teoria Econômica pelo Centro de Desenvolvimento e Planejamento Regional (Cedeplar) da Universidade Federal de Minas Gerais (UFMG), Belo Horizonte, MG, Brasil. Bolsista da Capes (Coordenação de Aperfeiçoamento de Pessoal de Nível Superior). E-mail: fvieira@cedeplar.ufmg.br

(3) Professor da Escola de Economia da Fundação Getúlio Vargas (FGV-SP), São Paulo, Brasil. Pesquisador do CNPq (Conselho Nacional de Desenvolvimento Científico e Tecnológico). O autor agradece o generoso suporte financeiro do CNPq. E-mail: marcio.holland@ fgv.br 
Fabrício de Assis C. Vieira / Márcio Holland

\section{Introdução}

Estudar o crescimento econômico brasileiro no longo prazo é, inquestionavelmente, uma tarefa desafiadora. As taxas de crescimento da renda (ou da renda per capita) observadas nos últimos 105 anos revelam um país com momentos de grande expansão e de forte contração recente. É fato curioso que, no começo do século XIX, a renda per capita brasileira era praticamente igual à dos Estados Unidos e que, um século depois, este último já apresentava renda per capita sete vezes maior do que o primeiro. Ao longo do século XX, houve sinais de nova convergência, que logo se desfez no último quarto do século. Desde então, o desempenho econômico brasileiro diverge francamente daquele observado nas principais economias desenvolvidas, ou mesmo perante diversas economias emergentes. O que explicaria esse fenômeno de fraco crescimento econômico, ou de dificuldade em convergir para taxas internacionais de crescimento?

Este trabalho analisa tal questão a partir do modelo de crescimento com restrição externa oriundo de Thirlwall para a economia brasileira no período 19002005 e subperíodos 1900-1970 e 1971-2005, com o uso da técnica de cointegração. A idéia de Thirlwall (1979) é que as causas para as diferenças nas taxas de crescimento entre os países estão ligadas a diferenças nas taxas de crescimento da demanda e não a acumulação de estoques de capital (físico e humano), tecnologia e outros fatores ligados à oferta (McCombie; Thirlwall, 1994).

De acordo com McCombie (1992), a significância estatística dos preços relativos não implica necessariamente que os termos de troca têm impactos, a longo prazo, nos fluxos de comércio. Assim, entre outros objetivos, espera-se demonstrar que os preços relativos (termos de troca) possuem um impacto na taxa de crescimento das importações, de forma que a exclusão dos termos de troca, na estimação da função de demanda por importações, afeta consideravelmente a elasticidade-renda da demanda por importações.

O trabalho está dividido em cinco seções, além desta introdutória. A primeira seção tratará do problema do crescimento econômico secular brasileiro, com a apresentação de dados empíricos e fatos teóricos. A segunda seção se dedica a apresentar o modelo de crescimento desenvolvido por Thirlwall. Na terceira seção será feita uma breve revisão da literatura empírica sobre os modelos de restrição externa, incluindo alguns dos resultados desses trabalhos empíricos. $\mathrm{Na}$ quarta seção serão apresentados os resultados empíricos para o crescimento econômico brasileiro, incluindo a fonte de dados usada e a metodologia. Por fim, a última seção se dedica às considerações finais.

Os resultados mostraram que os termos de troca são significativos na função de demanda por importações, alterando a elasticidade-renda, especialmente no subperíodo 1900-1970, e, segundo, que quando o modelo mais simples de 
Thirlwall é controlado pelos termos de troca, parece que tal variável afeta a performance econômica do país através das taxas de crescimento das importações.

10 problema do crescimento econômico secular brasileiro: dados empíricos e fatos teóricos

Com apoio do Gráfico 1, logo abaixo, vê-se que o crescimento médio secular do PIB brasileiro é razoavelmente significativo, em torno de $4,91 \%$ a.a. Contudo, assim o foi por conta de alguns períodos de elevadas taxas de crescimento, como o período do imediato pós-Segunda Guerra Mundial até meados da década de 1970, quando o país cresceu à taxa média de 7,5\% a.a., com picos no período do Plano de Metas (8,2\% a.a.); e também no conhecido "milagre econômico" (11,5\% a.a.). Contudo, exatamente logo ao final da década de 1970, o crescimento do PIB tem média bastante baixa (2,2\% a.a.) e apresenta taxas médias decrescentes desde então.

Gráfico 1

Brasil - Taxas de crescimento do PIB e tendência secular (1900-2005) - \% a.a.

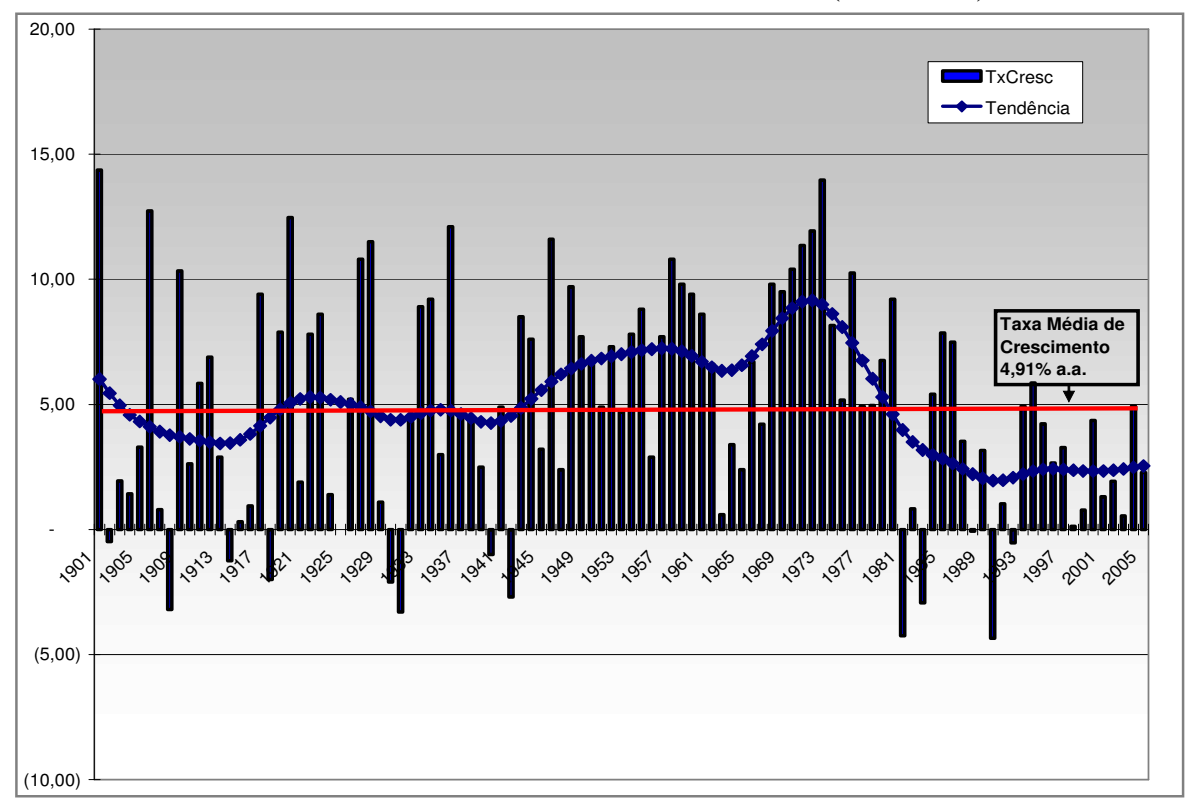

Nota: A linha de tendência de longo prazo foi obtida a partir do método de suavização conforme filtro de Hodrick-Prescott.

Fonte: Cálculos dos autores com base em dados do Ipeadata.

Em outras palavras, são 55 anos, de um total de 105, com taxas de crescimento econômico abaixo da linha da taxa média. O país não somente cresce cada vez menos, como também a variabilidade da taxa de crescimento aumenta em relação a sua média, especialmente após a década de 1990. Mais do que isso, é notória a quebra na linha de tendência logo ao final dos anos 1970. Note que o 
crescimento tendencial de longo prazo $^{4}$ fica em torno do crescimento médio nas primeiras quatro décadas do século XX; mas começa a se deslocar para além do crescimento médio ao final da década de 1940 até meados dos anos 1970. Contudo, após a década de 1980, o país assume uma trajetória de crescimento muito abaixo da sua taxa média.

Pode-se questionar sobre o quanto a economia brasileira diverge, em suas taxas de crescimento econômico, das economias internacionais. Em uma perspectiva secular, e ponderando o crescimento econômico pelo crescimento populacional, o Gráfico 2 revela algo muito similar ao Gráfico 1. A economia brasileira apresentou taxas de crescimento do PIB per capita bastante expressivas, se comparadas com as dos Estados Unidos. Contudo, a notável divergência nas taxas de crescimento da renda per capita toma lugar ao final da década de $1970 \mathrm{e}$ assim se mantém como um fenômeno quase que permanente. Note, ainda, que o ciclo de crescimento econômico brasileiro é bem mais errático do que o dos Estados Unidos.

Gráfico 2

Tendência secular do crescimento no Brasil e nos Estados Unidos (1900-2005)

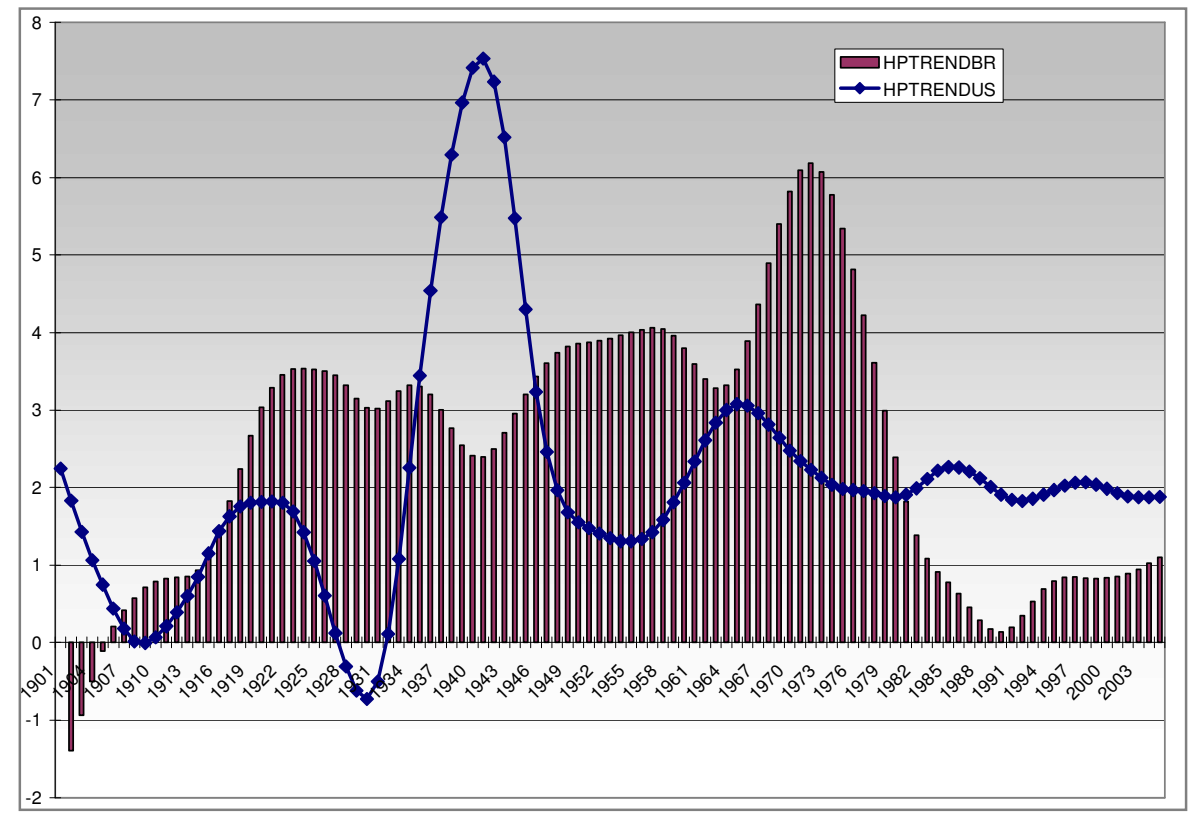

Nota: A linha de tendência de longo prazo foi obtida a partir do método de suavização conforme filtro de Hodrick-Prescott.

Fonte: Cálculos dos autores a partir de dados de taxas de crescimento da renda per capita, obtidas no Ipeadata, para o caso do Brasil, e em Johnston e Williamson (2006), para o caso da renda per capita dos Estados Unidos.

(4) Neste trabalho, as linhas de tendências de longo prazo das séries foram obtidas a partir da técnica de suavização conforme filtro de Hodrick-Prescott, que é, basicamente, um método de minimização de variância da série observada. 
Em termos de numerários, o PIB per capita dos Estados Unidos saiu de US\$ 4,9 mil, em 1900, e chegou a pouco mais de US\$ 23 mil, ao final dos anos 1970. Enquanto isso, o PIB per capita brasileiro saltou de US\$ 360 para US\$ 3,6 mil. Ou seja, um claro movimento convergente de renda. Contudo, desde então, a renda per capita brasileira mantém-se inquestionavelmente estagnada, sendo que, em 1980, ela era de US\$ 3,9 mil e, em 2005, chega a US\$ 4,2 mil. Nesse mesmo período, a renda per capita dos Estados Unidos salta de US\$ 23 mil para US\$ 37 mil.

As explicações sobre por que uma economia cresce pouco, ou mesmo, menos que outras economias, especialmente por um longo período de tempo, estão bastante distantes de algum consenso na literatura econômica. Muitos autores associam o fraco desempenho das economias às suas instituições e história de colonizações (Acemoglu, Johnson e Robinson, 2000), ou às questões geográficas (Sachs, 2001, 2003), ao grau de integração comercial com mercados internacionais (Krueger, 1998), ou ainda a fatores ligados ao acúmulo de capital humano (Romer, 1986, 1994; Barro, 1997; Glaeser et al., 2004, entre outros). Muito provavelmente esses fatores são realmente relevantes, afora ressalvas sobre endogeneidades e causalidades presentes no debate (Rodrik, 2004). Contudo, essa literatura pouco contempla outros fatores associados ao lado da demanda agregada, ou melhor, das restrições externas ao crescimento econômico. Nessa direção, vale pensar sobre as contribuições de Thirlwall (1979), McCombie e Thirlwall (1994). Neste trabalho, procura-se avaliar a importância dessas contribuições para explicar o desempenho do PIB brasileiro ao longo do século XX.

O fato é que o Brasil apresenta, indubitavelmente, elementos que poderiam validar diversas vertentes de explicações. De acordo com uma visão institucionalista, derivada da seminal contribuição de North (1981 e 1990), as origens de sua colonização estão, de fato, fortemente ligadas às atividades tipicamente extrativistas e, com isso, não se estabeleceram aqui colonizadores com suas boas instituições de origem. Em um processo retroalimentador ao longo do tempo, fizeram-se estabelecer níveis não satisfatórios de governança. Contudo, seria difícil explicar, através dessa abordagem, por que a economia brasileira cresceu tanto, pelo menos acima de sua média histórica, por aproximadamente trinta anos, de meados da década de 1940 a meados da década de 1970. Teria sido a qualidade institucional boa em algum momento da vida econômica do país e, por algum motivo, se alquebrado?

Neste caso, a abordagem de Rodrik (2004) também apresentaria algumas limitações. Afinal, mesmo controlando a taxa de crescimento e o desenvolvimento das instituições por fatores endógenos, ter-se-ia que considerar o fato de o crescimento econômico não ter propiciado boas instituições para que não somente elementos de "estímulos" ao crescimento, mas também de "sustentação" se 
manifestassem. De acordo com o autor: "In other words, we need to distinguish between stimulating economic growth and sustaining it. Solid institutions are much more important for the latter than for the former. Once growth is set into motion, it becomes easier to maintain a virtuous cycle with high growth and institutional transformation feeding on each other" (Rodrik, 2004:10, destaque do autor). Não teria sido aquele virtuoso crescimento econômico de meados dos anos 1940 a início dos anos 1970 suficiente para se construir boa jurisdição para sempre?

Outros fatores podem ter também grande apelo em explicar tão desafiante fenômeno. Afinal, de acordo com modelos de crescimento endógeno, a acumulação de capital humano é relativamente baixa no Brasil ao longo desse tempo. Dados do IBGE mostram que o nível médio de escolaridade do brasileiro se elevou, sem dúvida alguma, mas é ainda muito pouco perto do aumento do nível médio de escolaridade de outras economias que prosperaram mais. Mas não se pode negar também que a economia brasileira cresceu muito mais antes dos anos 1980, quando acúmulos de capital humano ainda eram incipientes.

Em Krueger (1998), economias que adotaram a estratégia do crescimento econômico voltado para fora (outer-oriented trade strategies) apresentaram resultados econômicos muito mais eficientes do que aquelas que viveram sob a égide do processo de substituição de importações. Notadamente, o Brasil cresceu muito mais durante a sua fase de substituição de importações. É certo que o processo de liberalização comercial adotado mais recentemente não removeu, de modo substancial, elementos do protecionismo nacional, e que medidas na direção da liberalização mais intensa far-se-iam necessárias a fim de avaliar se são realmente boas para o crescimento. Talvez a liberalização comercial seja boa para o crescimento, como defende Krueger (1998), mas também não se pode negar que, sob economia relativamente mais fechada, o país apresentou um dinamismo ainda maior.

Com a mesma preocupação em tentar revelar os fatores determinantes do crescimento secular no Brasil, uma interessante pergunta é levantada no trabalho de Pinheiro et al. (2004, p. 4), a saber, por que a economia brasileira cresceu tanto quando apresentava políticas econômicas consideradas "erradas"? Ou seja, no período em que o Brasil estava entre as economias de maiores taxas de crescimento, não havia preocupações com estabilidade de preços, predominava elevada proteção contra importações e ampla intervenção do Estado na economia. ${ }^{5}$ Nesse trabalho, os autores ainda apresentam resultados empíricos de regressões quando a taxa de crescimento é uma função de diversos fatores, como a abertura

(5) A tarifa média de importações era algo próximo a 10,5\% no auge do crescimento econômico brasileiro e caiu para menos de 7\%, quando a economia colapsa. Entre 1950 e 1980, a inflação média anual beirava a 35\%. Nesse mesmo período, o investimento público atingia 3\% do PIB, enquanto hoje em dia (2005) não chega a $1 \%$ do PIB. 
comercial, a inflação, a taxa de investimento, educação, termos de troca, entre outros. É aparentemente surpreendente o fato de que a abertura comercial está negativamente relacionada com o crescimento do PIB, assim como há indícios de que termos de troca podem ter uma correlação positiva com tal variável dependente, o que é relevante para este trabalho.

Em uma linha diferente do que se apresenta até então, Bresser-Pereira (2006) indica um caminho para a recuperação daquela fantástica performance econômica dos anos dourados. Cunhando o conceito de "novodesenvolvimentismo", como um paralelo ${ }^{6}$ ao desenvolvimentismo nos anos de 1940 a 1970, o autor revela a ausência de estratégias nacionais de desenvolvimento. Mas, o que seria essa estratégia nacional de desenvolvimento? Nas palavras do autor: "É mais do que uma simples ideologia, como é a ortodoxia convencional: é um conjunto de instituições e de políticas orientadas para o desenvolvimento econômico. É menos do que um projeto ou plano nacional porque não é formalizada, não tem documento com definição precisa de objetivos e de políticas a serem adotadas para alcançá-los, porque o acordo entre as classes sociais que lhe é inerente não tem nem texto nem assinaturas" (Bresser-Pereira, 2006, p. 16). Ao longo desse trabalho, o autor evidencia a importância em se considerar o "lado da demanda agregada", negligenciado pelo que o mesmo chama de "ortodoxia convencional".

Assim, apontar os fatores determinantes de por que e como a economia brasileira vem "ficando para trás", especialmente quando se compara com economias novo-emergentes (Índia e China), ou mesmo ao se observar bons desempenhos recentes em economias latino-americanas, ${ }^{8}$ está muito longe de um consenso entre economistas, acadêmicos e autoridades políticas. Com o propósito de procurar analisar a robustez de novas explicações, fora do eixo de literatura econômica mais amplamente difundida, é que se colocam os esforços deste artigo.

De acordo com a abordagem de crescimento adotada neste trabalho, que considera fundamental o lado da demanda na explicação do desempenho

(6) Trata-se efetivamente de um paralelo, dado que o autor aponta explícitas diferenças entre o desenvolvimentismo dos anos 1940 a 1970 e seu contexto histórico, com possível novo-desenvolvimentismo, cunhado sob disciplina fiscal, não-complacência com inflação, diferente papel do Estado e uma economia prudentemente aberta às exportações.

(7) Parafraseando um interessante livro de Haber (1997) intitulado "How Latin America fell behind: essays on the economic histories of Brazil and Mexico, 1800-1914". Da mesma forma que este trabalho analisa o que vem acontecendo desde 1900, na economia brasileira, nesse livro se identifica que a renda per capita do Brasil e do México era praticamente a mesma, em 1800, mas, em 1913, a renda per capita dos Estados Unidos já era quatro vezes maior do que a do México e sete vezes maior do que a do Brasil. Para os autores de ensaios que compõem este livro, o fraco desempenho latino-americano está muito mais associado às políticas internas $\mathrm{e}$ estruturas legais do que propriamente com algum modelo de dependência econômica do tipo colonial.

(8) Argentina, por exemplo, com cinco anos de crescimento econômico médio acima de $7 \%$ ao ano, após uma forte crise cambial, em 2001 e declaração de moratória de dívida. 
econômico dos países em desenvolvimento (incluindo o Brasil), a maior restrição sobre a taxa de crescimento da demanda nesses países seria o balanço de pagamentos, que expressa a relação entre a demanda pelas exportações e a demanda pelas importações. Assim, a restrição externa tem importância fundamental no crescimento de países como o Brasil e outros latino-americanos, que ainda apresentam uma desfavorável relação entre a elasticidade-renda da demanda por importações e a elasticidade-renda da demanda por exportações, apesar de importantes mudanças na pauta de exportações com a presença de produtos mais intensivos em tecnologia.

Nesse sentido, Thirlwall (1991) considera que países que produzem e exportam bens primários (e/ou menos elaborados tecnologicamente) terão uma restrição em seu crescimento (em relação aos países mais industrializados) devido ao desequilíbrio no balanço de pagamentos, caso os termos reais de troca entre bens primários e industriais não mudem. Assim, o autor considera que, para vários países, o crescimento é restringido pelo balanço de pagamentos antes que as restrições advindas da oferta venham à tona, o que difere da abordagem de Krugman (1989), para o qual diferenças nas taxas de crescimento dos países se devem principalmente às diferenças na taxa de crescimento da produtividade total dos fatores.

Observando as restrições externas à economia brasileira, a partir de uma aproximação pelos termos de troca, nota-se a forte correlação secular entre a especialização produtiva do setor externo brasileiro e o seu desempenho em termos de crescimento econômico. Com a ajuda do Gráfico 3, logo abaixo, podese dizer que a tendência ascendente ao crescimento econômico esteve muito fortemente associada à melhoria nos termos de troca. Ao mesmo tempo, o colapso nas taxas de crescimento econômico do país pode ser expresso também na extraordinária deterioração dos preços relativos. Mais uma vez, contudo, questões acerca da causalidade podem se colocar. Afinal, não se pode afirmar, a princípio, que o crescimento econômico seria explicado pela melhoria dos termos de troca, ou se, ao crescer, o país promove melhores condições de preços relativos. Entretanto, pode-se afirmar que há sinais de que o desempenho econômico se associa às restrições advindas do setor externo da economia.

O modelo de Thirlwall se diferencia dos modelos de crescimento econômico convencionais e da Teoria do Crescimento Endógeno. Enquanto nos modelos convencionais ${ }^{9}$ as taxas de crescimento dos fatores de oferta e do progresso tecnológico explicam as taxas diferenciadas de crescimento, como em

(9) O modelo neoclássico argumenta que o crescimento econômico é uma função do crescimento dos fatores de insumo. Costuma-se utilizar nesta abordagem uma função de produção do tipo Cobb-Douglas, com retornos constantes de escala, de forma que, com o capital e o trabalho crescendo a certa taxa e sem nenhuma mudança tecnológica, o produto da economia também crescerá nessa mesma taxa. 
Solow (1956), a literatura do crescimento endógeno enfatiza a importância, para o crescimento, dos retornos crescentes de escala e a produção de novos conhecimentos (tecnologias). Nesta abordagem, o trabalho de Romer (1986, 1990, 1994) pode ser considerado uma importante contribuição em termos da incorporação de mudanças tecnológicas e dos retornos crescentes em modelos de crescimento econômico endógenos. ${ }^{10}$

Gráfico 3

Brasil: Tendência secular do crescimento e dos termos de troca (1900-2005)

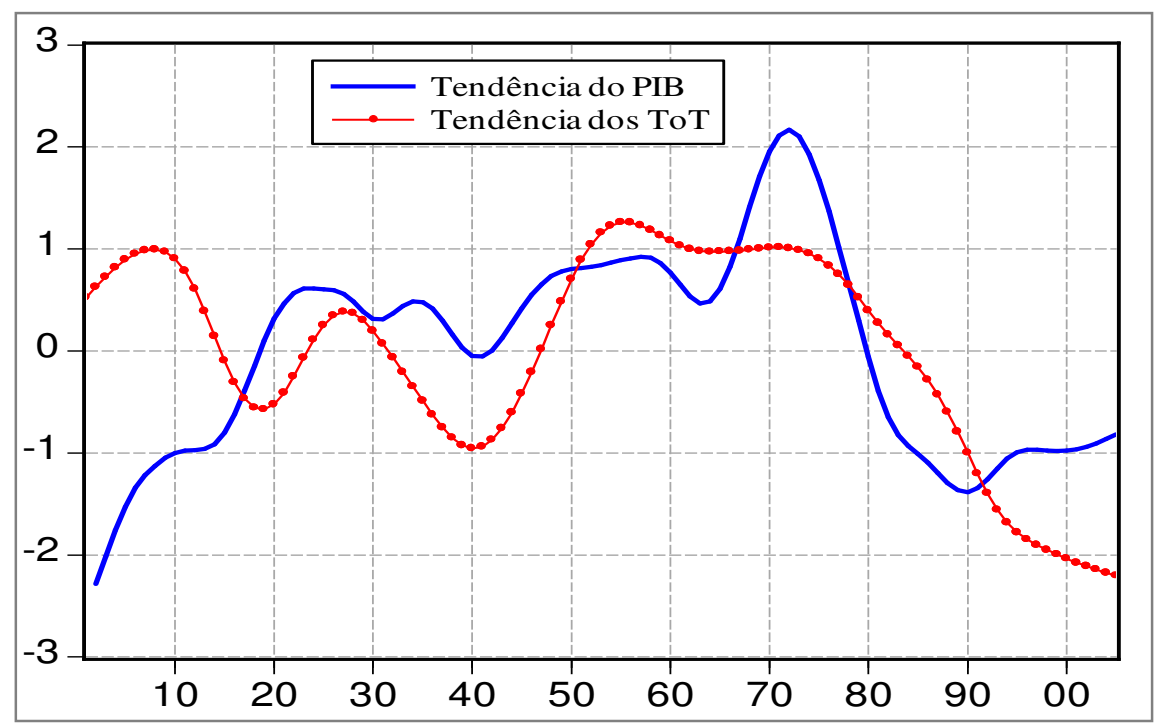

Nota: A linha de tendência de longo prazo foi obtida a partir do método de suavização conforme filtro de Hodrick-Prescott.

Fonte: Cálculos dos autores a partir de dados de taxas de crescimento da renda per capita, obtidas no Ipeadata e de dados de termos de troca obtidos na Oxford Latin American Economic History Database.

\section{0 modelo de crescimento em Thirlwall}

Seguindo a versão original de Thirlwall (1979), a primeira equação descreve a função de demanda por exportações, representada por:

$$
x=\eta\left(p_{d}-p_{f}\right)+\varepsilon(z)
$$

em que $x$ é a taxa de crescimento das exportações, $\eta(<0)$ é a elasticidade-preço da demanda por exportações, $\varepsilon(>0)$ é a elasticidade-renda da demanda por exportações, $z$ é a taxa de crescimento da renda mundial, $p_{d}$ é a

(10) Assim, as diferenças de renda entre os países são explicadas em modelos em que o progresso tecnológico se torna endógeno, ao invés de exógeno. 
taxa de crescimento dos preços domésticos e $p_{f}$ é a taxa de crescimento dos preços externos, de forma que $\left(p_{d}-p_{f}\right)$ é a taxa de crescimento dos preços relativos.

Já a função de demanda por importações pode ser descrita como uma equação que relaciona as importações com a competitividade e com a renda doméstica:

$$
m=\psi\left(p_{d}-p_{f}\right)+\pi(y)
$$

em que $m$ é a taxa de crescimento das importações, $\psi(>0)$ é a elasticidade-preço da demanda por importações, $y$ é a taxa de crescimento da renda nacional e $\pi(>0)$ é a elasticidade-renda da demanda por importações.

Assim, a condição de equilíbrio do balanço em conta corrente ${ }^{11}$ pode ser representada por:

$$
p_{d}+x=p_{f}+m
$$

Resolvendo a equação para a taxa de crescimento da renda real, temos:

$$
y_{B P}=[(1+\eta-\psi) / \pi]\left(p_{d}-p_{f}\right)+(\varepsilon / \pi) z
$$

Substituindo a taxa de crescimento da renda mundial $(z)$, da equação (1), temos a equação que relaciona a taxa de crescimento da renda compatível com o equilíbrio do balanço de pagamentos (BP):

$$
y_{B P}=[(1 / \pi)(1-\psi)]\left(p_{d}-p_{f}\right)+(1 / \pi) x
$$

Com a introdução dos fluxos externos de capital ao modelo, para o caso de países em desenvolvimento, ${ }^{12}$ Thirlwall e Hussain (1982) consideram que déficits em conta corrente podem ser financiados pelos capitais sem comprometer o equilíbrio do BP. A idéia dos autores é que o crescimento de longo prazo de países em desenvolvimento é restringido pela evolução dos fluxos externos de capital, exportações líquidas e termos reais de troca.

No entanto, apesar da modificação no modelo original proposta por Thirlwall e Hussain (1982) e apesar da equação (5) não considerar a influência dos

\footnotetext{
equilíbrio.

(11) Note que originalmente este modelo foi desenvolvido supondo que a conta de capital está em

(12) Conforme Moreno-Brid e Pérez (1999), estudos aplicados em economias avançadas mostraram que fluxos de capital e termos de troca não exercem grande influência nas taxas de crescimento de longo prazo dessas economias.
} 
termos de troca, o próprio Thirlwall acredita que o crescimento de longo prazo ${ }^{13}$ dos países - desenvolvidos e em desenvolvimento - não se distancia muito da razão entre a taxa de crescimento das exportações e a elasticidade-renda da demanda por importações.

Assim, adotando a suposição de que os preços relativos (termos de troca) são constantes e/ou que a condição de Marshall-Lerner se verifica, e se os fluxos de capitais não exercem influência na taxa de crescimento, a equação (5) se transforma na conhecida "regra simples" de Thirlwall:

$$
y_{B P}=x / \pi
$$

Segundo Hieke (1997), há controvérsia a respeito da inclusão ou não dos termos de troca na função de demanda por importações. De um lado, McGregor e Swales (1991) consideram que o conceito de Thirlwall expresso na equação acima requer estabilidade relativa nos termos de troca, sendo que estes não podem ser incluídos na análise empírica. Por outro lado, McCombie (1992) considera que tal argumento é inapropriado, pois o autor acredita que a significância estatística dos preços relativos não necessariamente implica que os termos de troca têm um impacto de longo prazo nos fluxos de comércio.

Atesoglu (1993), ao estimar a função de demanda por importações para a economia americana, verificou um pequeno, mas significante, impacto dos preços relativos na taxa de crescimento das importações, ao passo que, ao excluir os termos de troca, a elasticidade-renda da demanda não foi afetada consideravelmente pelos termos de troca, resultado favorável à Lei de Thirlwall.

Considerando a especificação de Hieke (1997), para a função de demanda por importações, a equação (2) pode ser modificada, resultando $\mathrm{em}^{14}$ :

$$
m=a+\psi(t t)+\pi(y)
$$

em que $a$ é uma constante e $\left(p_{d}-p_{f}\right)$, ou seja, a variação dos preços relativos, é considerada como sendo a variação dos termos de troca ou termos de comércio $(t t)$. Então, a taxa de crescimento da renda nacional compatível com o equilíbrio do balanço de pagamentos (modelo estendido) fica da seguinte forma:

$$
y_{B P}^{*}=[(1 / \pi)(1-\psi)](t t)+(1 / \pi) x
$$

(13) "In the short run, countries can run payments deficits financed by capital inflows, but they cannot finance ever-increasing inflows. Likewise, the terms of trade or real exchange rates may fluctuate in the short term, but in the long run it appears to remain relatively stable" (Thirlwall, 1997, p.380).

(14) Mais adiante, na estimação da função de demanda por importações, será usada a especificação desta função em termos logarítmicos, como em Hieke (1997): $\ln m=a+\psi(\ln t t)+\pi(\ln y)$. 
Podemos extrair várias proposições econômicas de (8):

a) A melhoria dos termos reais de troca, $(t t>0)$ ou $\left(p_{d}-p_{f}>0\right)$, estimula a taxa de crescimento da renda nacional compatível com o equilíbrio do balanço de pagamentos (BP), o que pode ser chamado de efeito puro dos termos de troca;

b) A alta dos preços internos (ou valor das exportações) em relação aos preços externos (ou valor das importações) reduz a taxa de crescimento da renda interna quando a soma das elasticidades-preço (negativas) é maior que um, ou seja, $(1+\eta+\psi)<0$;

c) A taxa de crescimento da renda nacional tem relação inversa com a propensão marginal a importar, que pode ser representada pela elasticidade-renda da demanda por importações $(\pi)$.

\section{Uma revisão da literatura empírica}

Existem vários testes paramétricos usados na análise do modelo de Thirlwall. No primeiro deles, roda-se uma regressão do crescimento observado $(y)$ sobre o crescimento previsto pelo modelo $\left(y_{b}\right)$ para um conjunto de países e verifica-se se o termo constante é zero e o coeficiente de regressão é igual a um; caso positivo, $y_{b}$ será um previsor da taxa real de crescimento (taxa observada de crescimento).

Este teste foi realizado por Thirlwall (1979) com a utilização do coeficiente de "rank correlation" de Spearman, com o intuito de testar o grau de associação entre a taxa de crescimento prevista pelo modelo e a taxa observada para os países da amostra, para os períodos 1953-1976 e 1951-1973. As elasticidades-renda usadas foram obtidas em Houthakker e Magee (1969) e os resultados validaram o modelo. Mas essa "regra simples" não considera a variação nos termos de troca (tampouco os fluxos de capitais). Neste ponto, Thirlwall (1997) afirma que as hipóteses de seu modelo podem parecer não realistas no curto prazo, mas tal modelo pretende explicar diferenças no crescimento de longo prazo entre os países, e não diferenças de curto prazo. Dessa forma, no curto prazo os termos de troca (taxa real de câmbio ou preços relativos) podem sofrer alterações, mas no longo prazo essa variável aparenta ser relativamente estável.

Nas críticas ao modelo de Thirlwall (1979), McGregor e Swales (1985) propuseram uma modificação naquele teste. Os autores regrediram a taxa de crescimento (em logaritmo) observada sobre a taxa teórica $\left(y_{b}\right)$ utilizando-se de uma regressão em "pooling", com vários países e usando equações diferentes das 
equações do teste de Thirlwall (1979). Assim, as hipóteses de igualdade do intercepto a zero e da declividade a 1 foram testadas e os resultados invalidaram a Lei de Thirlwall. Mas Thirlwall (2005) argumenta que tal teste só seria legítimo com a inclusão de todos os países do mundo, em que os déficits se igualariam aos superávits e as divergências existentes entre $y_{b}$ e $y$ se anulariam, o que não ocorre em uma amostra pequena.

Thirlwall (2005) também aponta problemas na aplicação do teste a países em que os déficits e superávits no balanço de pagamentos não se anulam, havendo tendência sistemática para que $y>y_{b}$, ou para $y<y_{b}$. Pode haver países em que $y \neq y_{b}$, resultando em um coeficiente de regressão diferente de um e levando à rejeição da teoria no tocante aos outros países da amostra.

Um outro teste paramétrico foi desenvolvido por McCombie (1997) e consiste em considerar cada país em separado e calcular a elasticidade-renda hipotética da demanda por importações $\left(\pi_{t}\right)$. No caso da "regra simples" $\left(y_{b}=x / \pi\right)$, obtém-se $\pi_{t}$ ao substituir $y_{b}$ pelo valor observado da taxa de crescimento $(y)$, ou seja, $\pi_{t}=x / y$. Então, compara-se a elasticidade hipotética com a elasticidade real (obtida na estimação da função de demanda por importação): caso $\pi_{t}$ não seja significativamente diferente de $\pi$, as taxas de crescimento estimada e observada também não divergirão significativamente. Esse teste paramétrico foi realizado por Moreno-Brid (2003), Santos et al. (2005), entre outros autores.

Em estudo para a economia espanhola, Alonso e Garcimartín (1998-1999) incluíram na função de demanda por exportação um índice de tecnologia, que tenta capturar mudanças estruturais significativas nas exportações espanholas. Os resultados desses autores mostraram que o comércio é sensível aos preços relativos e à tecnologia, mas o crescimento econômico espanhol não foi restringido pelo balanço de pagamentos - resultado obtido quando se adicionam os termos de troca à "regra simples" e quando se considera a variável tecnologia. No entanto, Alonso e Garcimartín (1998-1999) também validaram a "regra simples", e os autores consideram que tal resultado se deve ao efeito compensador da tecnologia, e não à irrelevância dos preços relativos. Assim, a piora dos termos de troca na economia espanhola no período 1965-1994 foi compensada pela melhoria tecnológica, de forma que o nível geral de competitividade da economia foi mantido.

Evidência favorável aos termos de troca pode ser vista em Moreno-Brid e Pérez (1999). Em estudo para várias economias da América Central, esses autores verificaram que a evolução dos termos de troca (juntamente com a evolução das 
exportações) foi determinante fundamental para o crescimento econômico dessas economias em desenvolvimento. Dados de Moreno-Brid e Pérez (1999) mostram que, no período 1950-1996, a Costa Rica apresentou uma maior taxa de crescimento econômico dentre os países pesquisados, com alta taxa de crescimento das exportações e pequena deterioração nos termos de troca. Por sua vez, a Nicarágua apresentou a menor taxa de crescimento do PIB e uma maior deterioração em seus termos de troca, sendo que a contribuição desta última variável para o crescimento da renda compatível com o equilíbrio do BP foi de $20 \%$, enquanto a contribuição do crescimento das exportações foi de $80 \%$.

Perraton (2003) acredita que a "regra simples" de Thirlwall pode ser aplicada em países desenvolvidos, em que os termos de troca e os fluxos de capital não são determinantes para a taxa de crescimento da economia. No entanto, o autor considera não realista assumir que países em desenvolvimento não experimentam nenhuma mudança nos preços relativos. Nesse sentido, estudos de López e Cruz $(1999,2000)$ para economias latino-americanas mostram que a taxa real de câmbio tem sido sujeita a grandes flutuações, dificultando aceitar a hipótese da existência de uma "taxa real de câmbio de equilíbrio de longo prazo".

O próprio Thirlwall (Thirlwall e Hussain, 1982; McCombie e Thirlwall, 1994) considera que mudanças nos termos de troca afetam a taxa de crescimento compatível com o equilíbrio do BP através dos efeitos diretos sobre a capacidade para importar e indiretamente via qualquer efeito de preço relativo sobre a demanda. Nesse ponto, estudo empírico de Atesoglu (1993) para a economia norte-americana mostrou que os preços relativos (termos de troca) tiveram um impacto significante na taxa de crescimento das importações norte-americanas, mas, ao excluir os termos de troca na estimação da função de demanda por importações, a elasticidade-renda não foi afetada consideravelmente, o que dá suporte à Lei de Thirlwall.

Diversos estudos que pretendem comprovar a validade desse modelo de crescimento para países em desenvolvimento, apesar de incluírem os termos de troca (preços relativos) na estimação da função de demanda por importações e/ou exportações, não introduzem os termos de troca à "regra simples". Assim, entre outros, podem-se citar os trabalhos de Moreno-Brid e Pérez (1999), Moreno-Brid (1999), Moreno-Brid (2003), McCombie e Thirlwall (1994), Ferreira (2001), Bertola, Higachi e Porcile (2002), Jayme Jr. (2003), Holland et al. (2004) e Santos et al. (2005).

Para o caso do México, Moreno-Brid (2003) justifica que, no período analisado (1967-1999), houve somente uma pequena variação (0,2\% a.a) nos termos de troca. Mesmo assim, o autor considera que a introdução da variável termos de troca (juntamente com a hipótese de mudanças na razão déficit em conta 
corrente sobre PIB) poderia melhorar significativamente a estimativa do crescimento econômico mexicano no período analisado.

Ainda nesse sentido, Holland et al. (2004) consideram que a não-inclusão dos termos de troca à "regra simples" seria uma limitação devido ao fato de que, em muitos países da amostra, verificou-se a não-estacionariedade da taxa real de câmbio em nível.

Assim, conforme veremos na próxima seção, a inclusão dos termos de troca à "regra simples" aumentou a taxa estimada de crescimento, devido à queda da elasticidade-renda da demanda por importações, de forma que a taxa de crescimento observada e estimada se tornam mais próximas.

Em estudo para a economia brasileira no período 1948-2004, Santos et al. (2005) estimaram a elasticidade-renda efetiva da demanda por importações considerando os termos de troca como uma das variáveis na função de demanda por importações. Os resultados empíricos de Santos et al. (2005) validaram a "regra simples" (Lei de Thirlwall) - especificação do modelo que não inclui os termos de troca. Por outro lado, Carvalho e Lima (2007), também para a economia brasileira nos períodos 1931-1993 e 1994-2004, mostram que o crescimento brasileiro foi aquele compatível com o equilíbrio do BP. Além disso, os autores mostraram que enquanto a contribuição dos termos de troca para o crescimento do PIB brasileiro foi da ordem de 1,4\% no período 1930-2004, no período inicial de análise (1931-1993) os termos de troca tiveram uma pequena contribuição negativa da ordem $0,7 \%$.

\section{Resultados empíricos}

\subsection{Dados e fontes}

Para verificarmos a aplicabilidade do modelo de crescimento com restrição no balanço de pagamentos à economia brasileira, utilizam-se, neste trabalho, dados anuais das variáveis PIB (Produto Interno Bruto), importações, exportações e termos de troca, todas expressas em logaritmo. As variáveis importações e exportações estão expressas em dólares americanos, enquanto a variável PIB está expressa em moeda nacional a preços constantes. Todas as variáveis foram obtidas na base de dados Ipeadata e em Oxford Latin American Economic History Database, para o caso dos termos de troca (razão entre o valor unitário das exportações e o valor unitário das importações).

O período de análise é de 1900 a 2005 e os subperíodos são, basicamente, os seguintes: 1900-1970 e 1971-2005. Assim, torna-se possível analisar o comportamento e possíveis mudanças na elasticidade-renda da demanda por importações no Brasil na fase de crescimento liderado pelas exportações de bens primários e crescimento baseado na industrialização, incluindo o período de 
substituições de importações (1900-1970), e na fase em que os fluxos externos de capitais passaram a ter grande importância no financiamento do crescimento brasileiro (1971-2005).

\subsection{Metodologia e procedimentos}

As taxas de crescimento da renda serão estimadas considerando dois modelos: a "regra simples", sem a inclusão dos termos de troca e fluxos de capitais; e o modelo dito estendido, ou seja, com a inclusão dos termos de troca. ${ }^{15}$ A idéia é verificar a contribuição das variações dos termos de troca à diferença entre o crescimento estimado pela "regra simples" e a taxa observada de crescimento, como em Thirlwall e Hussain (1982). Além disso, espera-se verificar o efeito da inclusão dos termos de troca sobre a elasticidade-renda da demanda por importações, o que será feito utilizando-se a especificação da função de demanda por importações de Hieke (1997).

O procedimento econométrico a ser utilizado será a análise de cointegração, que permite o estudo conjunto das dinâmicas de curto prazo e de longo prazo entre variáveis que são cointegradas. Ou seja, espera-se verificar se as variáveis importações, PIB e termos de troca se cointegram. Seguindo Enders (1995), as séries das variáveis econômicas $\left(x_{1}, x_{2}, \ldots x_{n}\right)$ se encontram em equilíbrio de longo prazo quando $\beta_{1} x_{1 t}+\beta_{2} x_{2 t}+\ldots \beta_{n} x_{n t}=0$; em que $x_{t}$ é um vetor e $\beta$ é o vetor de cointegração. O desvio do equilíbrio de longo prazo é chamado de erro de equilíbrio $\left(\varepsilon_{t}=\beta x_{t}\right)$. Considerando o componente aleatório $\varepsilon_{t}$ como estacionário e com média zero, $\beta_{1} x_{1 t}+\beta_{2} x_{2 t}+\ldots \beta_{n} x_{n t}=0$ passa a ser $\beta_{1} x_{1 t}+\beta_{2} x_{2 t}+\ldots \beta_{n} x_{n t}=\varepsilon_{t}$, ou seja, o vetor de equilíbrio de longo prazo se torna estacionário.

$\mathrm{Na}$ prática, será adotado o procedimento de cointegração conforme Johansen e Juselius (1990), que permite fazer análise de cointegração entre variáveis num contexto multivariado - sistema de equações com $n$ variáveis. Contudo, antes de proceder à análise de cointegração entre as séries das importações, PIB e termos de troca, é necessário verificar a ordem de integração dessas variáveis, o que será feito através dos testes de raiz unitária Augmented Dickey-Fuller (ADF) e Perron (PP, conforme Perron, 1989). Como os testes ADF estão sujeitos a um viés na presença de quebras estruturais, o que pode resultar numa não-rejeição da hipótese nula de raiz unitária, e como nossa amostra é secular e, portanto, sujeita à quebra estrutural (resultante, por exemplo, de um choque exógeno), usa-se também o teste de Perron para detectar a presença de raiz

(15) Futuras pesquisas incluirão a discussão sobre a conta de capital, especialmente para o período pós1970. 
unitária nas séries analisadas. Para testes de robustez sobre o método de Perron (1989), foram feitas também estimações conforme em Vogelsang e Perron (1998). ${ }^{16}$ Os resultados encontrados foram testados a partir dos valores críticos tabulados por Vogelsang e Perron (1998), mas não apresentados aqui por conveniência. Antecipa-se que os resultados conforme Perron (1989) se mantêm para o procedimento em Vogelsang e Perron (1998), o que tem sido observado na literatura em geral.

\subsection{Resultados}

$\mathrm{Na}$ verificação da ordem de integração do logaritmo das séries, conforme Tabelas de 6 a 8 do Anexo, vê-se que todas as séries são integradas de ordem 1, tanto pelos testes ADF quanto pelo teste PP (Perron, 1989), que é mais adequado para se fazer na presença de quebras estruturais. ${ }^{17}$ No tocante à variável termos de troca obtida junto ao Ipeadata, os testes, não incluídos no Anexo, ${ }^{18}$ indicaram que ela é estacionária em nível, de forma que não a incluímos no procedimento de cointegração.

Na construção de um VAR (vetor auto-regressivo) é necessário determinar quantas defasagens serão incorporadas ao modelo, o que é feito através dos critérios de informação Hannan-Quinn (HQ), Schwarz (SC) e Akaike (AIC). Assim, começa-se sempre com modelos que possuem o maior número de defasagens e verifica-se se a redução de defasagens está sendo coerente, no sentido de minimizar a soma dos erros. Nesse sentido, nosso procedimento foi começar nosso modelo utilizando cinco defasagens, para depois proceder à redução do número de defasagens. Exceto para um modelo, todos os demais foram

(16) Estes autores formulam um modelo aditivo com quebras no intercepto e tendência. A escolha do momento do choque é feita através da minimização da estatística t do componente auto-regressivo. O modelo inovacional também é utilizado e novamente é assumido o pressuposto de que nenhum choque ocorre em torno da hipótese nula. Os modelos foram estimados baseando-se no fato de que as séries temporais possuem apenas uma quebra estrutural. A data da quebra pode ser denotada conforme descrito no artigo de Perron e Vogelsang (1998), como $\mathrm{Tbc}$, onde $\mathrm{Tbc}<\mathrm{T}$, e $\mathrm{T}$ é o tamanho da amostra. O modelo aditivo presume que a quebra ocorre instantaneamente e, portanto, não é afetado pela dinâmica da série. O modelo inovacional, conforme dito antes, é mais bem aplicado em casos onde é mais razoável ver uma quebra ocorrendo ao longo do tempo. O teste de raiz unitária para esse tipo de modelo foi realizado conforme o procedimento de Dickey e Fuller (1979). Nesse trabalho, foi simulada uma quebra para alguns anos selecionados da amostra, sabendo-se que o ideal seria que fosse realizado para cada ano da amostra, tanto para o modelo aditivo quanto para o modelo inovacional. Contudo, dada a extensão da amostra, e dado o fato de que tais estimações foram realizadas apenas como teste de robustez para os testes de Perron (1989), optou-se por um procedimento mais parcimonioso, que foi a simulação de uma quebra para alguns anos selecionados da amostra.

(17) Os testes ADF foram rodados no PcGive 10 e os testes de raiz unitária PP foram rodados no Eviews 4. Já o procedimento de cointegração foi realizado no PcGive 10.

(18) Os testes ADF e PP para a variável termos de troca do Ipeadata, assim como os procedimentos como em Perron e Vogelsang (1998) não foram incluídos no Anexo por conveniência, mas estão disponíveis sob solicitação aos autores.

Economia e Sociedade, Campinas, v. 17, n. 2 (33), p. 17-46, ago. 2008. 
estimados com apenas uma defasagem; em caso de resultados conflitantes, optouse pelo critério de Schwarz - veja Tabelas de 9 a 14 no Anexo.

Após a escolha do número de defasagens a ser usada para cada modelo e cada período amostral, procedeu-se à estimação dos modelos a fim de verificar a possível presença de alguma relação de longo prazo entre as variáveis. Pelas estatísticas dos testes do traço e do máximo autovalor ${ }^{19}$ (conforme Tabelas 15 a 17), a hipótese nula de não-cointegração não pode ser rejeitada para os dois tipos de modelo - VAR (PIB, IMP) e VAR (PIB, IMP, TT) - tanto para 1900-2005, quanto para os subperíodos 1900-1970 e 1971-2005.

Dessa forma, dado que não foi encontrada nenhuma relação de longo prazo entre as variáveis PIB e importações, e entre PIB, importações e termos de troca, estimamos duas funções de demanda por importações para cada período, usando a diferença do logaritmo de cada variável. Além disso, estimamos também as funções de demanda por importações para cada período utilizando a variável termos de troca obtida no banco de dados do Ipeadata, no lugar da variável obtida em Oxford Latin American Economic History Database, e os resultados ${ }^{20}$ não se modificaram substancialmente.

Conforme Tabela 5, podemos observar que o período 1900-1970 foi o único em que a variável termos de troca foi significativa na equação da função de demanda por importações, de forma que obtemos duas elasticidades-renda da demanda por importações: uma para a função sem os termos de troca e outra com os termos de troca. Esse período também foi o único em que os termos de troca apresentaram uma variação média positiva, apesar de pequena $(0,22 \%)$. Já no subperíodo 1971-2005 e no período 1900-2005, os termos de troca tiveram variação média negativa de $-2,71 \%$ e $-0,79 \%$, respectivamente.

Apesar de as elasticidades-preço não terem sido significativas na função de demanda por importações para os períodos 1971-2005 e 1900-2005, a inclusão delas na equação alterou o valor da elasticidade-renda da demanda por importação. Assim, enquanto no subperíodo 1971-2005 a elasticidade-renda aumentou (Tabelas 2 e 4) e se aproximou bastante da elasticidade-renda hipotética $(2,97)$ calculada pela "regra simples", para 1900-2005 a elasticidade-renda caiu e também se aproximou da hipotética $(1,33)$.

A contribuição média dos termos de troca quando incluídos na regra simples é da seguinte grandeza: $\frac{\left(p_{d}-p_{f}\right)(1-\psi)}{\pi}$. Já a contribuição do

(19) As estatísticas do traço e do máximo autovalor consideradas foram aquelas ajustadas pelos graus de liberdade.

(20) Estes resultados não foram incluídos no Anexo por conveniência, mas estão disponíveis sob solicitação aos autores. 
crescimento das exportações é de $(1 / \pi) x$. Fazendo os cálculos, verifica-se que $\frac{\left(p_{d}-p_{f}\right)(1-\psi)}{\pi}$, para o período $1900-1970$, é $0,13 \%$, enquanto $(1 / \pi) x$ para o mesmo período é de 3,29\%, tal que a taxa de crescimento estimada é de 3,42\%.

Para o período 1900-1970, ambas as taxas estimadas de crescimento do PIB $\left(y_{B P}\right)$ se distanciaram da taxa de crescimento observada, mas a taxa estimada quando se usa a elasticidade obtida pela função de demanda por importações com a inclusão dos termos de troca foi maior do que a taxa correspondente à elasticidade obtida na função sem a inclusão dos termos de troca. Tal resultado indica a importância de incluir os termos de troca na função de demanda por importações, e vai contra a evidência empírica para a economia americana apresentada por Atesoglu (1993), em que a elasticidade-renda estimada não foi afetada consideravelmente pelos termos de troca.

Nesse estudo, ainda para o período 1900-1970, a inclusão dos termos de troca na função de demanda por importações fez cair o valor da elasticidade-renda de 1,51 para 1,22, que se aproximou da elasticidade-renda hipotética $(0,79)$. Esta, por sua vez, foi calculada ao substituir $y_{B P}$ pela taxa média observada de crescimento $(y)$ para o período de análise. No entanto, como a elasticidade estimada ainda diverge da elasticidade hipotética, nossa taxa média estimada de crescimento também se distancia da taxa observada, resultado que parece levantar limitações à "regra simples" de Thirlwall para o período em questão.

Não obstante, resultado favorável à inclusão dos termos de troca ao modelo original pode ser apreendido quando se calcula a taxa de crescimento da renda usando o modelo estendido, que incorpora termos de troca ${ }^{21}$. A taxa estimada de crescimento do PIB (3,42\% a.a.), por meio desse modelo estendido, foi um pouco maior do que a taxa estimada pela "regra simples", reduzindo a divergência entre a taxa observada 5,12\% a.a e a estimada. Esse aumento da taxa estimada de crescimento da renda também foi observado em outros estudos para a economia brasileira. Em Thirlwall, Fernandes e Siqueira (1983), para o período 1969-1978, a taxa estimada de crescimento passou de 5,28\% a.a. para 5,4\% a.a. quando se incorporou a variação dos termos de troca ao modelo simples, contra uma taxa observada de crescimento de $9,32 \%$ a.a, em banco de dados daqueles autores.

Com a inclusão dos fluxos de capitais ao modelo e para o período 19651978, os autores acima estimaram uma taxa de crescimento maior do que a taxa observada. Também para o caso brasileiro, Thirlwall e Hussain (1982) incluíram

(21) A equação deste modelo é $y_{B P}^{*}=[(1 / \pi)(1-\psi)](t t)+(1 / \pi) x$. 
os fluxos de capitais ao modelo simples para o período 1951-1969 e verificaram que a contribuição dos fluxos de capitais para a diferença entre a taxa estimada e a real foi de $5,4 \%$, enquanto a contribuição dos termos de troca foi de $0,1 \%{ }^{22}$

Conforme Tabelas 3 e 4 do Anexo, a contribuição da variação dos termos de troca para a diferença entre a taxa estimada e a observada foi pequena $(0,13 \%) .{ }^{23} \mathrm{O}$ uso do modelo estendido aumentou em 0,13 p.p. a taxa estimada de crescimento, mas ainda há uma diferença (1,70 p.p.), provavelmente causada pela não-inclusão da variável fluxo de capitais em nosso modelo.

Um fato curioso verificado foi que, no período 1971-2005, a taxa estimada pela "regra simples" se aproximou mais da taxa observada. Enquanto a taxa média estimada foi de 4,16\%, a taxa média observada foi de 3,66\%, conforme Tabela $1 \mathrm{e}$ Gráfico 1 do Anexo. Tal resultado pode ser explicado pelo alto crescimento das exportações. Em comparação com os outros períodos, 1971-2005 foi o período de maior crescimento das exportações (média de 10,9\% a.a.), das importações (média de $9,2 \%$ a.a.), e o período de maior queda nos termos de troca $(-2,79 \%$ a.a.).

\section{Considerações finais}

Este trabalho realizou uma primeira aproximação para a aplicação do modelo de crescimento econômico de Thirlwall com restrição no Balanço de Pagamentos, para o caso da economia brasileira, no período 1900-2005. Tal modelo se difere dos modelos neoclássicos de crescimento econômico, bem como dos modelos de crescimento endógeno, ao atribuir como causas para as diferentes taxas de crescimento da renda dos países as diferenças nas taxas de crescimento da demanda. De acordo com esta abordagem, no caso brasileiro, a maior restrição sobre a taxa de crescimento da demanda seria o balanço de pagamentos. Como se observou na parte introdutória deste trabalho, há uma enorme avenida na agenda de pesquisa sobre causas plausíveis para a dinâmica das taxas de crescimento do PIB brasileiro, especialmente, de uma perspectiva de longo prazo.

Entre os principais resultados empíricos encontrados, destaca-se que os termos de troca parecem afetar de modo considerável a elasticidade-renda da demanda por importações. Este resultado sugere que a Lei de Thirlwall, em sua versão original, ("regra simples") aponta para alguns limites empíricos, pelo

(22) Este trabalho intencionalmente reservou para outra oportunidade a pesquisa sobre o papel dos fluxos de capitais, especialmente por conta do fato de que já há uma grande literatura altamente divergente sobre o referido tema, e uma nova abordagem deveria ter um caráter mais cuidadoso. Veja, por exemplo, a pesquisa mais recente de Prasad, Raghuram e Subramanian (2006), que apontam para o fato de economias em desenvolvimento mais dependentes dos fluxos de capitais cresceram menos. De outro lado, não se pode negar que períodos de maior liquidez internacionais estão associados com um pouco mais de crescimento econômico nas economias latino-americanas (Holland; Vieira, 2005).

(23) Contribuição bastante parecida com a verificada em Thirlwall e Hussain (1982). 
menos para o caso do Brasil. Assim, os preços relativos (termos de troca) foram significantes na função de demanda por importações. De outra parte, a inclusão dos termos de troca na chamada "regra simples" de Thirlwall teve pouca contribuição $(0,13 \%)$ na explicação da taxa estimada de crescimento econômico de longo prazo para o caso do Brasil. Ou seja, os termos de troca devem mesmo afetar o crescimento econômico de longo prazo no Brasil, mas muito provavelmente através da estrutura de especialização das importações e exportações, mais do que diretamente sobre as taxas de crescimento. A estrutura de especialização das importações e exportações, por sua vez, têm papel essencial no crescimento econômico brasileiro.

Este último resultado vai de encontro com as evidências em Thirlwall e Hussain (1982) e Thirlwall, Fernandes e Siqueira (1983), em que a contribuição dos termos de troca, para a diferença entre a taxa estimada e a taxa observada, é pequena. Dessa forma, parece haver evidências de que os fluxos de capitais possuem algum papel na explicação da diferença entre a taxa estimada de crescimento e a taxa observada. Por outro lado, a não-significância estatística dos termos de troca na função de demanda por importações no subperíodo 1971-2005 aponta também para o papel dos fluxos de capitais, e não dos termos de troca, na explicação do crescimento econômico brasileiro nesse subperíodo.

O aumento da elasticidade-renda da demanda por importações do subperíodo 1900-1970 para o subperíodo 1971-2005, de 1,51 para 2,62, nos diz algo sobre a importância de se dividir a amostra em subperíodos. Evidências apontadas por Hieke (1997), para a economia americana, também mostram mudanças nos valores da elasticidade-renda de um subperíodo para outro.

Por fim, dado que a taxa de crescimento da renda tem relação inversa com a elasticidade-renda da demanda e dado que os termos de troca possuem algum impacto nessa elasticidade e na taxa de crescimento estimada da renda, pode-se dizer que se o Brasil quiser aumentar sua taxa de crescimento de longo prazo, é necessária a adoção de políticas que aumentem sua competitividade internacional. Assim, políticas que permitam que haja um aumento na taxa de crescimento das exportações de bens mais elaborados tecnologicamente, bem como políticas que favoreçam uma queda na elasticidade-renda da demanda por importações seriam bastante benéficas para o crescimento econômico brasileiro.

\section{Referências bibliográficas}

ACEMOGLU, Daron; JOHNSON, Simon; ROBINSON, James A. The colonial origins of comparative development: an empirical investigation. Washington, DC: NBER, Jun. 2000. (NBER Working Paper, n. 7771). 
ALONSO, José A.; GARCIMARTÍN, Carlos A new approach to balance-of-payments constraint: some empirical evidence. Journal of Post Keynesian Economics, v. 21, n. 2, 1998/1999.

ATESOGLU, H. Sonmez. Balance-of-payments-constrained growth. Journal of Post Keynesian Economics, v. 15, n. 4, p. 507-516, 1993.

Balance-of-payments-constrained model and its implications for the United States. Journal of Post Keynesian Economics, v. 19, n. 3, p. 327-336, 1997.

BARRO, R. J. Determinants of economic growth: a cross-country empirical study. Cambridge, MA: MIT Press, 1997.

BERTOLA, L.; HIGACHI, H.; PORCILE, G. Balance-of-payments-constrained growth in Brazil: a test of Thirlwall's law. Journal of Post Keynesian Economics, v. 25, n. 123, 2002.

BRESSER-PEREIRA, Luiz Carlos. O novo-desenvolvimentismo e a ortodoxia convencional. São Paulo em Perspectiva, São Paulo, Seade, v. 20, n. 1, jan./mar. 2006.

CARVALHO, V. R; LIMA, Gilberto T. A restrição externa e a perda de dinamismo da economia brasileira: investigando relações entre estrutura produtiva e crescimento econômico. In: ENCONTRO NACIONAL DE ECONOMIA, 35, Recife, dez. 2007. Anais Eletrônicos...

DICKEY, D. A.; FULLER, W. A. Distribution of the estimators for autoregressive time series with a unit root. Journal of the American Statistical Association, v. 74, p. 427-431, 1979.

ENDERS, W. Applied econometric time series. New York: John Wiley \& Sons, 1995.

FERREIRA, Alex. A lei de crescimento de Thirlwall. Dissertação (Mestrado)-Instituto de Economia, Universidade Estadual de Campinas, 2001.

GLAESER, E. et al. Do institutions cause growth? Journal of Economic Growth, v. 9, p. 271-303, 2004.

HABER, Stephen. How Latin America fell behind: essays on the economic histories of Brazil and Mexico, 1800-1914. Stanford University Press, 1997.

HIEKE, Hubert. Balance-of-payments-constrained growth: a reconsideration of the evidence for the US economy. Journal of Post Keynesian Economics, v. 19, n. 3, p. 313326, 1997.

HOLLAND, M.; VIEIRA, F. Foreign liquidity, economic opening and growth in Latin American economies. Revista Brasileira de Economia. v. 59, n. 2, 2005.

; ___ CANUTO, O. Economic growth and the balance-of-payments constraint in Latin America. Investigación Económica, v. LXIII, ene./mar. 2004.

HOUTHAKKER, H. S.; MAGEE, S. P. Income and price elasticities in world trade. Review of Economics and Statistics, v. 51, n. 2, May 1969.

IPEA. Ipeadata: dados macroeconômicos e regionais. Disponível em: http://www.ipeadata.gov.br/ipeaweb.dll/ipeadata?12131968. 
JAYME Jr., F. G. Balance-of-payments constrained economic growth in Brazil. Revista de Economia Política, v. 23, n. 1, 2003.

JOHANSEN, S.; JUSELIUS, K. Maximum likelihood estimation and inference on cointegration - With application to the demand for money. Oxford Bulletin of Economics and Statistics, v. 52, p. 169-210, 1990.

JOHNSTON, L. D.; WILLIAMSON, S. H. The annual real and nominal GDP for the United States, 1790 - Present. Economic History Services, Oct. 2005. Disponível em: http://www.eh.net/hmit/gdp/

KRUEGER, A. O. Why trade liberalization is good for economic growth. Economic Journal, v. 108, p. 1513-1522, Sept. 1998. Disponível em: http://uclibs.org/PID/895

KRUGMAN, P. Differences in income elasticities and trends in real exchange rates. European Economic Review, v. 33, n. 5, May 1989.

LÓPEZ, J.; CRUZ, A. Crecimiento económico y tipo de cambio real: un análisis de cointegración para América Latina. Momento Económico, n. 102, p. 23-33, mar./abr. 1999.

Thirlwall's law and beyond: the Latin American experience. Journal of Post Keynesian Economics, v. 22, n. 3, Spring 2000.

MCCOMBIE, J. S. L. Thirwall's 'law' and balance of payments constrained growth more on the debate. Applied Economics, v. 24, p. 493-512, 1992.

On the empirics of balance-of-payments-constrained growth. Journal of Post Keynesian Economics, v. 19, p. 345-375, 1997.

; THIRLWALL A. P. Economic growth and the Balance of Payments constraint. New York: St. Martin's Press, 1994.

MCGREGOR, P.G.; SWALES, J. K. Professor Thirlwall and balance of payments constrained growth. Applied Economics, v. 17, p. 17-32, 1985.

Thirwall's law and balance of payments constrained growth: further comment on the debate. Applied Economics, v. 23, p. 9-20, 1991.

MORENO-BRID, J. C. Mexico's economic growth and the balance of payments constraint: a cointegration analysis. International Review of Applied Economics, v. 13, n. 2, p. 150-159, 1999.

; PÉREZ, Esteban. Balance-of-payments-constrained growth in Central America: 1950-96. Journal of Post Keynesian Economics, v. 22, p. 131-147, 1999.

Capital flows, interests payments and the balance-of-payments constrained growth model: a theoretical and empirical analysis. Metroeconomica, v. 54, n. 2, 2003.

NORTH, Douglass C. Structure and change in economic history. New York: Norton \& Co., 1981.

Institutions, institutional change, and economic performance. Cambridge: Cambridge University Press, 1990.

OXFORD. Oxford Latin American Economic History Database. Disponível em http://oxlad.qeh.ox.ac.uk/ 
PERRATON, J. Balance of payments constrained economic growth and developing countries: an examination of Thirlwall's hypothesis. International Review of Applied Economics, v. 17, n. 1, 2003.

PERRON, P. The great crash, the oil price shock, and the unit root hypothesis. Econometrica, Econometric Society, v. 57, n. 6, p. 1361-1401, Nov. 1989.

PINHEIRO, Armando C. et al. Brazilian economic growth, 1900-2000: lessons and policy implications. Economic and Social Study Series. IAB, Washington, D.C. May 2004.

PRASAD, E., RAGHURAM, R.; SUBRAMANIAN, A. Foreign capital and economic growth. Aug. 11, 2006. http://www.kansascityfed.org/PUBLICAT/SYMPOS/2006/pdf/ PrasadRajanSubramanian.0811.pdf

RODRIK, D. Getting institutions right. CES-DICE Report, Journal of International Comparisons, p. 10-15, Summer 1994. 2004. Disponível em: http://translate.google.com.br/translate?hl=pt-BR\&sl=en\&u=http://ksghome.harvard.edu/ $\sim$ drodrik/papers.html\&sa=X\&oi=translate \&resnum $=1 \& \mathrm{ct}=$ result\&prev $=/ \mathrm{search} \% 3 \mathrm{Fq} \% 3 \mathrm{D}$ ksghome $\% 2 \mathrm{Bharvard} \% 26 \mathrm{hl} \% 3 \mathrm{Dpt}-\mathrm{BR} \% 26 \mathrm{sa} \% 3 \mathrm{DG}$

ROMER, P. M. Increasing returns and long-Run growth. Journal of Political Economy, v. 94, p. 1002-1037, 1986.

Endogenous technological Change. The Journal of Political Economy, v. 98, n. 5, Part 2: The problem of development: a Conference of the Institute for the Study of Free Enterprise Systems, p. S71-S102, Oct. 1990.

. The origins of endogenous growth. Journal of Economic Perspectives, v. 8, n. 1, p. 3-22, 1994.

SACHS, Jeffrey D. Tropical underdevelopment. Washington, DC: NBER, Feb. 2001. (NBER Working Paper, n. w8119).

Institutions don't rule: direct effects of geography on per capita income. Washington, DC: NBER, Feb. 2003. (NBER Working Paper, n. 9490).

SANTOS, Antônio T. L; LIMA, Gilberto T.; CARVALHO, Veridiana R. A restrição externa como fator limitante do crescimento econômico brasileiro: um teste empírico. In: ENCONTRO NACIONAL DE ECONOMIA, 33, Natal, dez. 2005. Anais Eletrônicos...

SOLOW R. M. Contribution to the theory of economic growth. Quarterly Journal of Economics, v. 70, n. 1, p. 65-94, 1956.

THIRLWALL A. P. The balance of payments constraint as an explanation of international growth rates differences. Banca Nazionale del Lavoro Quarterly Review, v. 128, p. 45-53, 1979.

Professor Krugman's 45-degree rule. Journal of Post Keynesian Economics, v. 14, n. 1, p. 131-147, 1991.

Reflections on the concept of balance-of-payments-constrained growth. Canterbury, Journal of Post Keynesian Economics, v. 19, n. 3, 1997.

Natureza do crescimento econômico: um referencial alternativo para compreender o desempenho das nações. Brasília: Ipea, 2005. 
THIRLWALL, A. P.; HUSSAIN, M. N. The balance of payments constraint, capital flows and growth rates differences between developing countries. Oxford Economic Papers, v. 34, p. 498-509, 1982.

; FERNANDES, Cândido Lima; SIQUEIRA, Marcelo Piancastelli. Endividamento externo, balanço de pagamentos e crescimento econômico no Brasil 1965-1978. Fundação João Pinheiro, Belo Horizonte, v. 13, n. 1², p. 6-17, jan./fev. 1983.

VOGELSANG, T .J.; PERRON, P. Additional tests for a unit root allowing the possibility of breaks in the trend function. International Economic Review, v. 39, n. 4, p. 1073-1100, Nov. 1998. 


\section{Anexo}

Gráfico 1

Taxas de crescimento estimadas e observadas

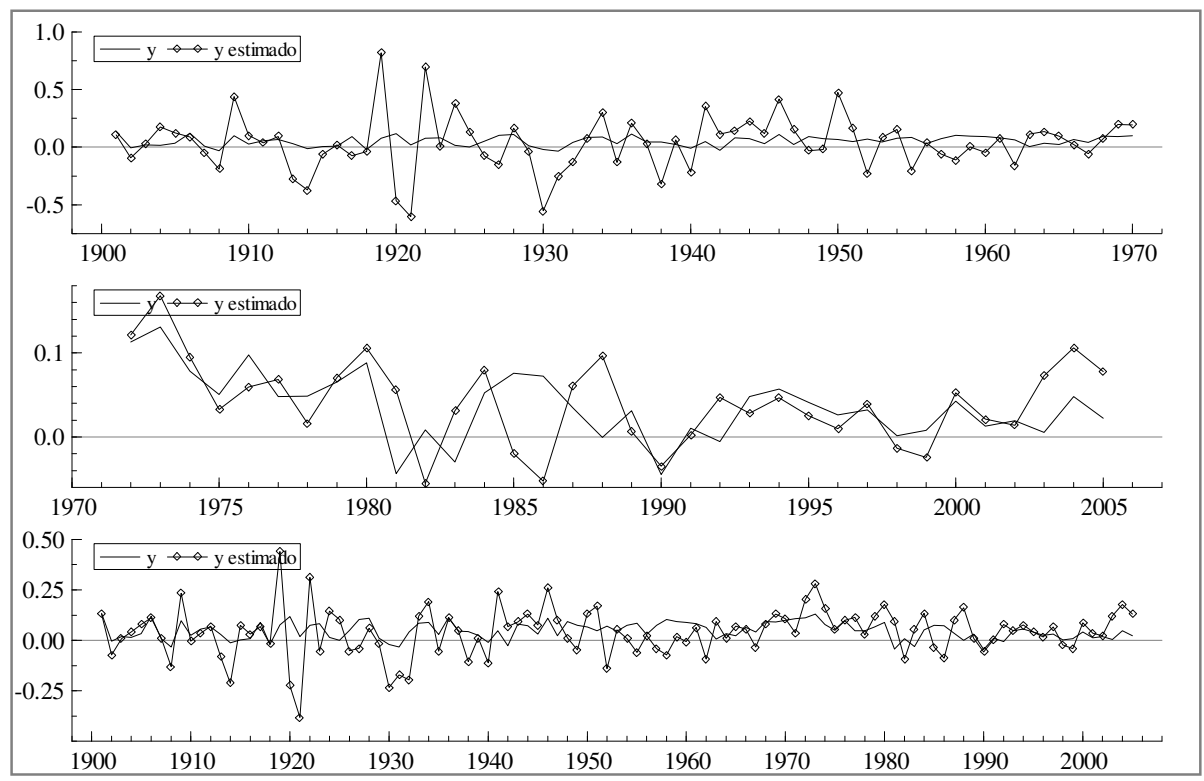

Tabela 1

Taxas médias (\%) anuais de crescimento das exportações, importações, do PIB observado e do PIB estimado

\begin{tabular}{c|c|c|c|c|c}
\hline Período & $x$ & $m$ & $y$ & $y_{B P}$ Sem TT* & $y_{B P}$ Com TT** \\
\hline $1900-1970$ & 4.05 & 4.55 & 5.12 & 2.68 & 3.29 \\
\hline $1971-2005$ & 10.90 & 9.18 & 3.66 & 4.16 & - \\
\hline $1900-2005$ & 6.28 & 6.25 & 4.70 & 4.01 & - \\
\hline
\end{tabular}

* PIB estimado usando a elasticidade-renda obtida na função de demanda por importações sem a inclusão dos termos de troca

** PIB estimado usando a elasticidade-renda obtida na função de demanda por importações com a inclusão dos termos de troca

Tabela 2

Elasticidades estimadas e elasticidades hipotéticas (equilíbrio)

\begin{tabular}{c|c|c|c|c}
\hline Período & $\pi$ Sem TT & $\pi$ Com TT & $\pi_{t}$ Modelo simples & $\pi_{t}$ Modelo estendido \\
\hline $1900-1970$ & 1.51 & 1.22 & 0.79 & 0.82 \\
\hline $1971-2005$ & 2.62 & $2.95^{*}$ & 2.97 & - \\
\hline $1900-2005$ & 1.56 & $1.26^{*}$ & 1.33 & - \\
\hline
\end{tabular}

* elasticidades calculadas no modelo em que os termos de troca não foram significativos 
Tabela 3

Comparação entre as taxas médias anuais de crescimento, usando a regra simples e o modelo estendido

\begin{tabular}{c|c|c|c|c|c}
\hline Período & $\begin{array}{c}y \\
(\%)\end{array}$ & $\begin{array}{c}y_{B P} \\
(\%)\end{array}$ & $\begin{array}{c}y-y_{B P} \\
(\mathrm{p} . \mathrm{p} .)\end{array}$ & $\begin{array}{c}y_{B P}^{*} \\
(\%)\end{array}$ & $\begin{array}{c}y-y_{B P}^{*} \\
\text { (p.p. })\end{array}$ \\
\hline $1900-1970$ & 5.12 & 3.29 & +1.83 & 3.42 & +1.70 \\
\hline $1971-2005$ & 3.66 & 4.16 & -0.50 & - & - \\
\hline $1900-2005$ & 4.70 & 4.01 & +0.69 & - & - \\
\hline
\end{tabular}

Tabela 4

Divergências entre a taxa real e a estimada, contribuição para a diferença entre elas e variação média dos termos de troca em cada período

\begin{tabular}{c|c|c|c|c|c}
\hline Período & $\begin{array}{c}y \\
(\%)\end{array}$ & $\begin{array}{c}y_{B P} \\
(\%)\end{array}$ & $\begin{array}{c}\text { Diferença } \\
(\mathrm{p} . \mathrm{p} .)\end{array}$ & $\begin{array}{c}\text { Efeito dos } \\
\text { movimentos dos } \\
\text { termos de troca }\end{array}$ & $\begin{array}{c}\text { Variação média dos } \\
\text { termos de troca }(\%)\end{array}$ \\
\hline $1900-1970$ & 5.12 & 3.29 & +1.83 & +0.13 & 0.22 \\
\hline $1971-2005$ & 3.66 & 4.16 & -0.50 & - & -2.71 \\
\hline $1900-2005$ & 4.70 & 4.01 & +0.69 & - & -0.79 \\
\hline
\end{tabular}

Tabela 5

Função de demanda por importações por períodos: $\ln m_{t}=a+\pi\left(\ln y_{t}\right)+\psi\left(\ln t t_{t}\right)$

\begin{tabular}{|c|c|c|c|c|}
\hline Período & Constante & Elasticidade-renda & Elasticidade-preço & $D W$ \\
\hline \multicolumn{5}{|c|}{$1900-1970$} \\
\hline Sem tt ${ }^{a}$ & $\begin{array}{l}-0.0237 \\
(-0.581)\end{array}$ & $\begin{array}{l}1.5113 \\
(2.52)\end{array}$ & - & $1.95 * *$ \\
\hline Com tt ${ }^{b}$ & $\begin{array}{l}-0.0087 \\
(-0.224)\end{array}$ & $\begin{array}{c}1.2292 \\
(2.14)\end{array}$ & $\begin{array}{c}0.2728 \\
(2.03)\end{array}$ & $2.03 * *$ \\
\hline \multicolumn{5}{|c|}{ 1971-2005 } \\
\hline Sem $\mathrm{tt}^{c}$ & $\begin{array}{c}-0.0673 \\
(-1.86)\end{array}$ & $\begin{array}{c}2.6203 \\
(4.63)\end{array}$ & - & $1.28 * *$ \\
\hline Com $\mathrm{tt}^{d}$ & $\begin{array}{c}-0.0737 \\
(-2.04)\end{array}$ & $\begin{array}{c}2.9550 \\
(5.07)\end{array}$ & $\begin{array}{c}-0.1912 \\
(-1.13)\end{array}$ & $1.5^{* *}$ \\
\hline \multicolumn{5}{|c|}{$1900-2005$} \\
\hline Sem tt ${ }^{e}$ & $\begin{array}{l}-0.0133 \\
(-0.487)\end{array}$ & $\begin{array}{c}1.5672 \\
(3.87)\end{array}$ & - & $1.88^{* *}$ \\
\hline Com tt $f$ & $\begin{array}{l}0.0148 \\
(0.572)\end{array}$ & $\begin{array}{c}1.2638 \\
(3.13)\end{array}$ & $\begin{array}{c}0.1208 \\
(1.13)\end{array}$ & $1.78^{* *}$ \\
\hline
\end{tabular}

Notas: Os números entre parênteses indicam os $t$-values;

a: foram incluídas dummies para os anos 1914, 1921, 1930, 1947 e 1951;

b: foram incluídas dummies para os anos 1914, 1921, 1931,1947 e 1951;

c: foi incluída uma dummy para o ano 1914 e uma step dummy para 1988-1998;

d: foram incluídas dummies para os anos 1974 e 1985 e uma step dummy para 1988-1998;

e: foram incluídas dummies para os anos 1914, 1921, 1924, 1930, 1931, 1947, 1951, 1953, 1974 e uma step dummy para 1990-1998;

** os testes de normalidade e estacionariedade indicaram que os resíduos são normais e estacionários. 
Tabela 6

Teste de raiz unitária para LN PIB

\begin{tabular}{l|c|c}
\hline LN PIB & ADF (1) & PP \\
\hline Tendência e Constante & Aceita 1 RU (10\%) & Aceita 1 RU (10\%) \\
\hline Constante & Aceita 1 RU (10\%) & Aceita 1 RU (10\%) \\
\hline Sem Constante e sem tendência & não significativo & Aceita 1 RU (10\%) \\
\hline DLN PIB & ADF $(0)$ & PP \\
\hline Tendência e Constante & Rejeita RU & Rejeita RU \\
\hline Constante & Rejeita RU & Rejeita RU \\
\hline Sem Constante e sem tendência & não significativo & não significativo \\
\hline
\end{tabular}

Tabela 7

Teste de raiz unitária para LN Importações

\begin{tabular}{l|c|c}
\hline LN Importações & ADF (1) & PP \\
\hline Tendência e Constante & Aceita 1 RU (10\%) & Aceita 1 RU (10\%) \\
\hline Constante & não significativo & não significativo \\
\hline Sem Constante e sem tendência & não significativo & Aceita 1 RU (10\%) \\
\hline DLN Importações & ADF(0) & PP \\
\hline Tendência e Constante & não significativo RU \\
\hline Constante & Rejeita RU & Rejeita RU \\
\hline Sem Constante e sem tendência & não significativo & não significativo \\
\hline
\end{tabular}

Tabela 8

Teste de raiz unitária para LN Termos de Troca

\begin{tabular}{l|c|c}
\hline LN Termos de Troca & ADF (0) & PP \\
\hline Tendência e Constante & Não significativo & Não significativo \\
\hline Constante & Aceita 1 RU (10\%) & Aceita 1 RU (10\%) \\
\hline Sem Constante e sem tendência & Não significativo & Não significativo \\
\hline DLN Termos de Troca & ADF (0) & PP \\
\hline Tendência e Constante & Não significativo & Não significativo \\
\hline Constante & Rejeita RU & Rejeita RU (1\%) \\
\hline Sem Constante e sem tendência & Não significativo & Rejeita RU (1\%) \\
\hline
\end{tabular}

Tabela 9

Seleção da ordem do VAR (PIB, IMP): 1900-1970

\begin{tabular}{l|c|c|c|c|c}
\hline Modelo & Defasagens & P & SC & HQ & AIC \\
\hline 1 & 5 & 22 & -2.7065 & -3.1480 & -3.4364 \\
\hline 2 & 4 & 18 & -2.7598 & -3.1210 & -3.3569 \\
\hline 3 & 3 & 14 & -2.9886 & -3.2695 & -3.4530 \\
\hline 4 & 2 & 10 & -3.2178 & -3.4185 & -3.5496 \\
\hline 5 & 1 & 6 & -3.3732 & -3.4936 & -3.5722 \\
\hline
\end{tabular}


Tabela 10

Seleção da ordem do VAR (PIB, IMP, TT): 1900-1970

\begin{tabular}{l|c|c|c|c|c}
\hline Modelo & Defasagens & P & SC & HQ & AIC \\
\hline 1 & 5 & 48 & -2.5155 & -3.4787 & -4.1079 \\
\hline 2 & 4 & 39 & -2.8049 & -3.5875 & -4.0988 \\
\hline 3 & 3 & 30 & -3.2212 & -3.8233 & -4.2165 \\
\hline 4 & 2 & 21 & -3.7433 & -4.1647 & -4.4400 \\
\hline 5 & 1 & 12 & -3.8991 & -4.1399 & -4.2972 \\
\hline
\end{tabular}

Tabela 11

Seleção da ordem do VAR (PIB, IMP): 1971-2005

\begin{tabular}{l|c|c|c|c|c}
\hline Modelo & Defasagens & P & SC & HQ & AIC \\
\hline 1 & 5 & 22 & -3.7233 & -4.4222 & -4.7509 \\
\hline 2 & 4 & 18 & -4.0773 & -4.6490 & -4.9180 \\
\hline 3 & 3 & 14 & -4.3236 & -4.7683 & -4.9775 \\
\hline 4 & 2 & 10 & -4.7568 & -5.0744 & -5.2238 \\
\hline 5 & 1 & 6 & -4.6799 & -4.8705 & -4.9602 \\
\hline
\end{tabular}

Tabela 12

Seleção da ordem do VAR (PIB, IMP, TT): 1971-2005

\begin{tabular}{l|c|c|c|c|c}
\hline Modelo & Defasagens & P & SC & HQ & AIC \\
\hline 1 & 5 & 48 & -5.0600 & -6.5847 & -7.3019 \\
\hline 2 & 4 & 39 & -4.5615 & -5.8004 & -6.3831 \\
\hline 3 & 3 & 30 & -4.5667 & -5.5196 & -5.9679 \\
\hline 4 & 2 & 21 & -5.1622 & -5.8293 & -6.1431 \\
\hline 5 & 1 & 12 & -5.4903 & -5.8715 & -6.0508 \\
\hline
\end{tabular}

Tabela 13

Seleção da ordem do VAR (PIB, IMP): 1900-2005

\begin{tabular}{l|c|c|c|c|c}
\hline Modelo & Defasagens & P & SC & HQ & AIC \\
\hline 1 & 5 & 22 & -3.0876 & -3.4266 & -3.6573 \\
\hline 2 & 4 & 18 & -3.1806 & -3.4580 & -3.6466 \\
\hline 3 & 3 & 14 & -3.3412 & -3.5570 & -3.7037 \\
\hline 4 & 2 & 10 & -3.4904 & -3.6445 & -3.7493 \\
\hline 5 & 1 & 06 & -3.5658 & -3.6582 & -3.7211 \\
\hline
\end{tabular}

Tabela 14

Seleção da ordem do VAR (PIB, IMP, TT): 1900-2005

\begin{tabular}{l|c|c|c|c|c}
\hline Modelo & Defasagens & P & SC & HQ & AIC \\
\hline 1 & 5 & 48 & -3.2310 & -3.9707 & -4.4738 \\
\hline 2 & 4 & 39 & -3.5227 & -4.1237 & -4.5325 \\
\hline 3 & 3 & 30 & -3.8619 & -4.3242 & -4.6387 \\
\hline 4 & 2 & 21 & -4.1907 & -4.5143 & -4.7344 \\
\hline 5 & 1 & 12 & -4.3178 & -4.5027 & -4.6285 \\
\hline
\end{tabular}


Tabela 15

Estatísticas do traço e do Máximo Autovalor: 1900-1970

\begin{tabular}{c|c|c|c|c}
\hline \multicolumn{5}{c}{$1900-1970-$ cointegração entre importações e PIB } \\
\hline \multirow{2}{*}{ Rank } & Trace test (T-nm) & {$[$ Prob] } & Max test (T-nm) & {$[$ Prob] } \\
\hline 0 & 10.91 & {$[0.221]$} & 8.55 & {$[0.333]$} \\
\hline 1 & 2.35 & {$[0.125]$} & 2.35 & {$[0.125]$} \\
\hline \multicolumn{4}{|c|}{$1900-1970-$ cointegração entre importações, PIB e termos de troca } \\
\hline Rank & Trace test (T-nm) & {$[$ Prob] } & Max test (T-nm) & {$[$ Prob] } \\
\hline 0 & 21.36 & {$[0.346]$} & 11.83 & {$[0.576]$} \\
\hline 1 & 9.52 & {$[0.325]$} & 7.00 & {$[0.498]$} \\
\hline 2 & 2.52 & {$[0.112]$} & 2.52 & {$[0.112]$} \\
\hline
\end{tabular}

Tabela 16

Estatísticas do traço e do Máximo Autovalor: 1971-2005

\begin{tabular}{c|c|c|c|c}
\hline \multicolumn{5}{|c}{$1971-2005-$ cointegração entre importações e PIB } \\
\hline Rank & Trace test (T-nm) & {$[$ Prob] } & Max test (T-nm) & {$[$ Prob] } \\
\hline 0 & 8.85 & {$[0.386]$} & 7.94 & {$[0.394]$} \\
\hline 1 & 0.92 & {$[0.338]$} & 0.92 & {$[0.338]$} \\
\hline \multicolumn{5}{|c|}{ 1971-2005 - cointegração entre importações, PIB e termos de troca } \\
\hline Rank & Trace test (T-nm) & {$[$ Prob] } & Max test (T-nm) & {$[$ Prob] } \\
\hline 0 & 15.35 & {$[0.761]$} & 7.75 & {$[0.909]$} \\
\hline 1 & 7.59 & {$[0.517]$} & 6.11 & {$[0.606]$} \\
\hline 2 & 1.48 & {$[0.223]$} & 1.48 & {$[0.223]$} \\
\hline
\end{tabular}

Tabela 17

Estatísticas do traço e do Máximo Autovalor: 1900-2005

\begin{tabular}{l|c|c|c|c|c}
\hline \multicolumn{5}{|c}{$1900-2005-$ cointegração entre importações e PIB } \\
\hline Rank & Trace test (T-nm) & {$[$ Prob] } & Max test (T-nm) & {$[$ Prob] } \\
\hline 0 & 9.87 & {$[0.297]$} & 7.58 & {$[0.432]$} \\
\hline 1 & 2.29 & {$[0.130]$} & 2.29 & {$[0.130]$} \\
\hline \multicolumn{4}{|c|}{ Rank } & $1900-2005-$ cointegração entre importações, PIB e termos de troca & {$[$ Prob] } \\
\hline 0 & Trace test (T-nm) & {$[$ Prob] } & Max test (T-nm) & {$[0.168]$} \\
\hline 1 & 25.57 & {$[0.146]$} & 17.21 & {$[0.602]$} \\
\hline 2 & 8.36 & {$[0.435]$} & 6.14 & {$[0.136]$} \\
\hline
\end{tabular}

